\title{
Preparation and Performance of an Adsorption Type Gel Plugging Agent as Enhanced Oil Recovery Chemical
}

\author{
Xiaoping Qin, Jiapeng Zheng, Liangchuan Li, Cuixia Li, Guiling Sun, \\ Haiwei Lu, and Tong Peng \\ Drilling and Production Technology Research Institute, PetroChina Jidong Oilfield Company, Tangshan 063004, China \\ Correspondence should be addressed to Xiaoping Qin; 948801727@qq.com
}

Received 5 August 2015; Revised 30 September 2015; Accepted 7 October 2015

Academic Editor: Marinos Pitsikalis

Copyright ( 2015 Xiaoping Qin et al. This is an open access article distributed under the Creative Commons Attribution License, which permits unrestricted use, distribution, and reproduction in any medium, provided the original work is properly cited.

\begin{abstract}
A novel adsorption type gel plugging agent (ATGPA) was prepared using acrylamide (AM), acrylic acid (AA), diallyl dimethyl ammonium chloride (DMDAAC), 2-acrylamido-2-methylpropanesulfonate (AMPS), formaldehyde (HCHO), resorcinol $\left(\mathrm{C}_{6} \mathrm{H}_{6} \mathrm{O}_{2}\right)$, and thiocarbamide $\left(\mathrm{CH}_{4} \mathrm{~N}_{2} \mathrm{~S}\right)$ as raw materials under mild conditions. ATGPA was characterized by infrared (IR) spectroscopy, elemental analysis, and scanning electron microscope (SEM). It was found that ATGPA exhibited higher elastic modulus $\left(G^{\prime}\right)$ and viscous modulus $\left(G^{\prime \prime}\right)$ than AM/AA gel plugging agent (AAGPA) under the same scanning frequency. It was also found that ATGPA had moderate temperature resistance and salt tolerance. Core plugging tests results indicated that ATGPA could achieve up to higher plugging rate $\left(P_{R}\right)$ than AAGPA (97.2\% versus $\left.95.7 \%\right)$ at $65^{\circ} \mathrm{C}$. In addition, ATGPA possessed stronger antiscouring ability by core plugging experiments at $65^{\circ} \mathrm{C}$.
\end{abstract}

\section{Introduction}

Gel plugging agent plays an important role in the field of enhanced oil recovery (EOR) for high water cut oilfield $[1,2]$. However, the current widely used gel plugging agent, prepared by polyacrylamide (PAM) or partially hydrolyzed polyacrylamide (HPAM), cannot completely meet the requirements due to the poor antiscouring ability in porous medium and the degradation under high temperature or high salinity [3-7].

In general, while increasing the concentration of gel plugging agent is beneficial to enhance the sealing strength, the antiscouring ability of the gel plugging agent is not helpful. And this method will lead to a substantial increase in the cost of gel plugging agent. Recently, many studies have demonstrated that the adsorption property of composite material could be significantly improved by copolymerization with a cationic functional monomer with high charge density [8-10]. The composite material containing cationic functional monomer, such as polymeric adsorbent, chelating resin, and polymer supported catalyst, may exhibit more satisfactory adsorption stability owing to the effect of quaternary ammonium basic ion [10-14]. However, there are no papers about the application of cationic functional monomer with high charge density in EOR to develop antiscouring ability of gel plugging agent.

Furthermore, many research works have indicated that functional polyacrylamide with $-\mathrm{SO}_{3}{ }^{-}$groups, such as 2acrylamido-2-methylpropanesulfonate (AMPS), vinyl sulfonate (VS), p-styrenesulfonate (SS), and sodium (acrylamido) methanesulfonate (SAM), could yield a better product which may be salt tolerance and temperature resistance under the reservoir conditions [15-17]. And the application of AMPS is pretty widespread.

Keeping in mind these fundamental conditions, herein, diallyl dimethyl ammonium chloride and AMPS were introduced into gel plugging agent aiming to obtain satisfying antiscouring ability, temperature resistance, and salt tolerance.

\section{Experimental}

2.1. Chemicals and Reagents. Acrylamide (AM, $\geq 99.0 \%)$, acrylic acid (AA, $\geq 99.5 \%$ ), 2-acrylamido-2-methylpropanesulfonate (AA, $\geq 99.5 \%$ ), diallyl dimethyl ammonium chloride (DMDAAC, $\geq 99.5 \%)$, sodium hydroxide $(\mathrm{NaOH}, \geq 96.0 \%)$, polyoxyethylene (10) octylphenyl ether (OP-10, $\geq 99.5 \%$ ), 
TABLE 1: Composition and TDS of injecting water.

\begin{tabular}{lccccccc}
\hline Composition & $\mathrm{Na}^{+}+\mathrm{K}^{+}$ & $\mathrm{Ca}^{2+}$ & $\mathrm{Mg}^{2+}$ & $\mathrm{SO}_{4}{ }^{2-}$ & $\mathrm{Cl}^{-}$ & $\mathrm{HCO}_{3}^{-}$ & $\mathrm{TDS}^{-}$ \\
\hline Content (wt\%) & 0.0232 & 0.0099 & 0.0024 & 0.0009 & 0.0321 & 0.0473 & 0.1158 \\
\hline
\end{tabular}

sodium hydrogen sulfite $\left(\mathrm{NaHSO}_{3}, \geq 58.5 \%\right.$ ), ammonium persulfate $\left(\left(\mathrm{NH}_{4}\right)_{2} \mathrm{~S}_{2} \mathrm{O}_{8}, \geq 98.0 \%\right)$, ethanol $\left(\mathrm{C}_{2} \mathrm{H}_{5} \mathrm{OH}\right.$, $\geq 99.7 \%$ ), formaldehyde ( $\mathrm{HCHO}, 37 \%$ aqueous), resorcinol $\left(\mathrm{C}_{6} \mathrm{H}_{6} \mathrm{O}_{2}, \geq 99.7 \%\right)$, thiocarbamide $\left(\mathrm{CH}_{4} \mathrm{~N}_{2} \mathrm{~S}, \geq 98.0 \%\right)$, sodium chloride $(\mathrm{NaCl}, \geq 99.5 \%)$, magnesium chloride hexahydrate $\left(\mathrm{MgCl}_{2} \cdot 6 \mathrm{H}_{2} \mathrm{O}, \geq 98.0 \%\right)$, calcium chloride anhydrous $\left(\mathrm{CaCl}_{2}, \geq 96.0 \%\right)$, potassium chloride $(\mathrm{KCl}, \geq 99.5 \%)$, sodium sulfate $\left(\mathrm{Na}_{2} \mathrm{SO}_{4}, \geq 99.0 \%\right)$, and sodium bicarbonate $\left(\mathrm{NaHCO}_{3}\right.$, $\geq 99.5 \%$ ) were purchased from Chengdu Kelong Chemical Reagent Factory (Sichuan, China). All chemicals and reagents were used as received without any further purification. Water was deionized by passing through an ion-exchange column and doubly distilled.

2.2. Preparation of ATGPA. The AM/AA/AMPS/DMDAAC copolymer was synthesized by free radical copolymerization. $17.58 \mathrm{~g}$ AM, $4.53 \mathrm{~g}$ AA, $3.87 \mathrm{~g}$ AMPS, $4.02 \mathrm{~g}$ DMDAAC, $2.51 \mathrm{~g}$ $\mathrm{NaOH}, 0.12 \mathrm{~g}$ OP-10 (used as emulsifier), and $0.15 \mathrm{~g} \mathrm{NaHSO}_{3}-$ $\left(\mathrm{NH}_{4}\right)_{2} \mathrm{~S}_{2} \mathrm{O}_{8}$ initiator ( $1 / 1 \mathrm{~mol}$ ratio) were taken along with $70 \mathrm{~g}$ distilled water in a three-necked flask. Residual oxygen was removed by nitrogen $\left(\mathrm{N}_{2}\right)$ being bubbled through the solution for $30 \mathrm{~min}$ under constant stirring at $35^{\circ} \mathrm{C}$. The threenecked flask was kept in a water bath with magnetic stirring unless otherwise indicated. Copolymerization was carried out at $35^{\circ} \mathrm{C}$ under $\mathrm{N}_{2}$ atmosphere for $6 \mathrm{~h}$. After being cooled to room temperature $\left(25^{\circ} \mathrm{C}\right)$, the products were separated by precipitation using ethanol and dried in vacuum oven at $40^{\circ} \mathrm{C}$ for $24 \mathrm{~h}$ to give the powdered copolymer samples. $6.08 \mathrm{~g}$ $\mathrm{HCHO}$ (37 wt\% aqueous), $0.60 \mathrm{~g} \mathrm{C}_{6} \mathrm{H}_{6} \mathrm{O}_{2}$, and $0.15 \mathrm{~g} \mathrm{CH}_{4} \mathrm{~N}_{2} \mathrm{~S}$ were added into a solution of copolymer $(3.0 \mathrm{~g})$ in $1000 \mathrm{~mL}$ distilled water at room temperature with magnetic stirring to yield ATGPA.

The AM/AA copolymer without AMPS and DMDAAC (replaced by additional AM and AA) was synthesized by using the same synthesis method. The AM/AA gel plugging agent (AAGPA) was prepared using the AM/AA copolymer, $\mathrm{HCHO}, \mathrm{C}_{6} \mathrm{H}_{6} \mathrm{O}_{2}$, and $\mathrm{CH}_{4} \mathrm{~N}_{2} \mathrm{~S}$ via the same method.

2.3. Characterization. ATGPA and AAGPA solutions $(0.6 \mathrm{wt} \%)$ were prepared with distilled water. These solutions were placed in a constant temperature box, and the crosslinking reaction took $72 \mathrm{~h}$. All characterization and evaluation were carried out until all of the plugging agent was crosslinked unless otherwise indicated. Infrared (IR) spectra of ATGPA and AAGPA were measured with potassium bromide $(\mathrm{KBr})$ pellets using a PerkinElmer RX-1 spectrophotometer. The elementary analysis of ATGPA and AAGPA was carried out with a Vario EL-III elemental analyzer. The microstructures of ATGPA and AAGPA were observed by a scanning electron microscope (SEM).
2.4. Temperature Resistance and Salt Tolerance. ATGPA and AAGPA solutions $(0.6 \mathrm{wt} \%)$ were prepared with distilled water. These plugging agents were placed at different temperature, and the time required for the formation of the gel was $72 \mathrm{~h}$. Then the apparent viscosity of these plugging agents was tested using Brookfield DV-III viscometer at different temperatures.

The plugging agents solutions were prepared by using brine with different salt concentration $\left(\mathrm{NaCl}\right.$ or $\left.\mathrm{CaCl}_{2}\right)$. These plugging agents solutions needed to be aged for $72 \mathrm{~h}$ at $65^{\circ} \mathrm{C}$. The apparent viscosity of these plugging agents was measured via Brookfield DV-III viscometer at $65^{\circ} \mathrm{C}$.

2.5. Viscoelasticity. Viscoelasticity measurements of ATGPA and AAGPA were conducted on a HAAKE RS 600 Rotational Rheometer (Germany). The test system was coneplate system and the rotor was P35TiL in viscoelasticity measurements. The stress was $1.0 \mathrm{~Pa}$, and the scanning range of frequency $(f)$ was $0.1-10.0 \mathrm{~Hz}$.

2.6. Core Plugging Tests. Two sandstone cores were used for core plugging experiments. The cores were dried at $65^{\circ} \mathrm{C}$, and then their diameter, length, gas permeability, and porosity were measured by using a SCMS-B2 core multiparameter measurement system. A Hassler core holder was used with 3.5 $\mathrm{MPa}$ confining pressure and 1.5 $\mathrm{MPa}$ backpressure [18]. The core was saturated with injecting water at $0.1 \mathrm{~mL} / \mathrm{min}$, and then the plugging agent solution $(0.6 \mathrm{wt} \%$, non-crosslinked) was injected at $0.1 \mathrm{~mL} / \mathrm{min}$ until injection mass reached 0.6 pore volume $(\mathrm{PV})$. In 3 days, the core was flooding with injecting water at $0.1 \mathrm{~mL} / \mathrm{min}$ to obtain stable injection pressure. All the core plugging procedures were conducted at $65^{\circ} \mathrm{C}$. Chemical composition and total dissolved solids (TDS) of the injecting water are listed in Table 1. The plugging rate is calculated with the following equation:

$$
P_{R}=\frac{\left(K_{\mathrm{wb}}-K_{\mathrm{wa}}\right)}{K_{\mathrm{wb}}} \times 100
$$

where $P_{R}$ is plugging rate, $\%, K_{\mathrm{wb}}$ is aqueous phase permeability before plugging, $\mathrm{mD}$, and $K_{\mathrm{wa}}$ is aqueous phase permeability after plugging, $\mathrm{mD}$.

Flow chart of the core plugging experiments is shown in Figure 1.

\section{Results and Discussion}

3.1. IR Spectra Analysis. The structures of ATGPA and AAGPA were confirmed by IR spectra as illustrated in Figure 2. ATGPA was confirmed by strong absorptions at $3433.2 \mathrm{~cm}^{-1}$ (-OH stretching vibration and $-\mathrm{NH}$ stretching vibration), $2924.3 \mathrm{~cm}^{-1}\left(-\mathrm{CH}_{2}\right.$ stretching vibration), 
TABLE 2: The test results of elementary analysis of ATGPA and AAGPA.

\begin{tabular}{lcccc}
\hline \multirow{2}{*}{ Element } & \multicolumn{2}{c}{ AAGPA } & \multicolumn{2}{c}{ ATGPA } \\
& Theoretical value (\%) & Found value (\%) & Theoretical value (\%) & 47.2 \\
Found value (\%) \\
\hline $\mathrm{C}$ & 47.2 & 48.2 & 6.7 & 79.4 \\
$\mathrm{~N}$ & 6.5 & 6.9 & 7.7 & 8.3 \\
$\mathrm{~S}$ & 8.8 & 9.1 & 2.0 & 1.9 \\
\hline
\end{tabular}

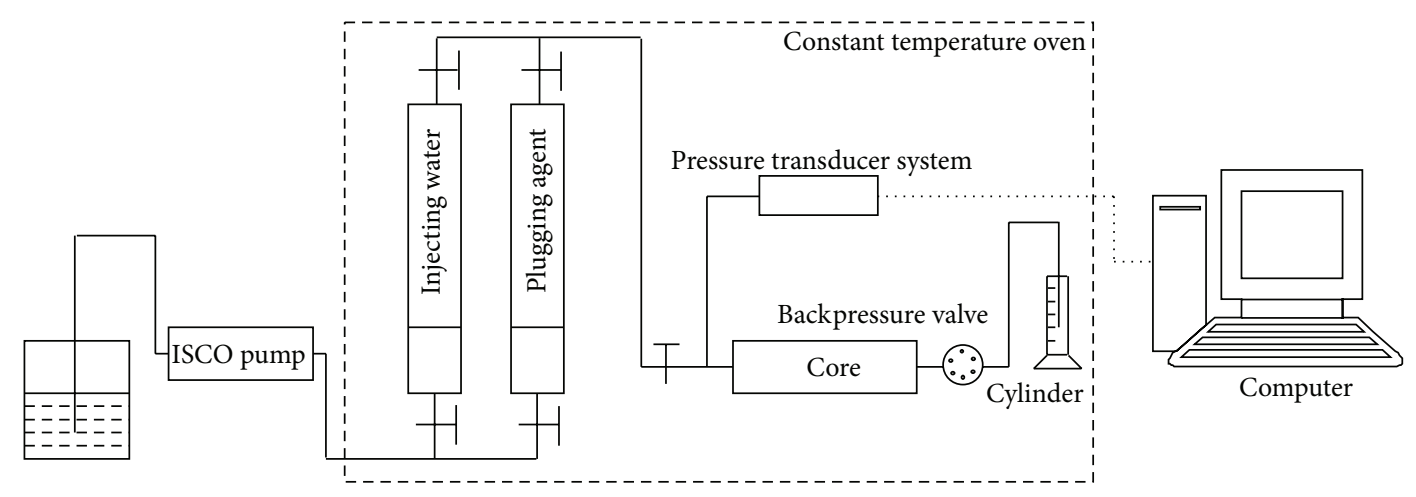

FIGURE 1: Flow chart of the core plugging experiments.

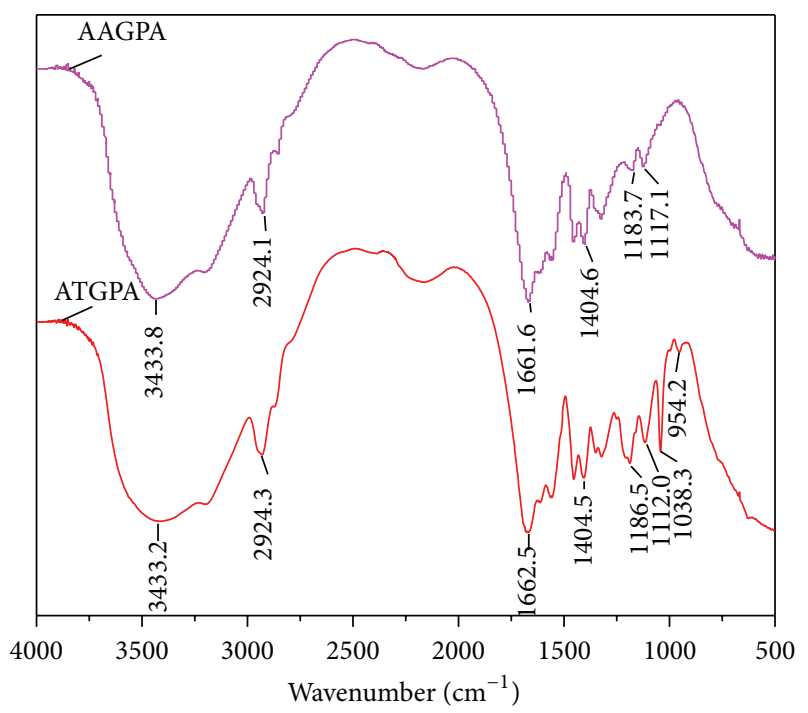

FIgURE 2: IR spectra of ATGPA and AAGPA.

$1662.5 \mathrm{~cm}^{-1}$ ( $\mathrm{C}=\mathrm{O}$ stretching vibration), $1404.5 \mathrm{~cm}^{-1}$ (C$\mathrm{N}$ stretching vibration), $1186.5 \mathrm{~cm}^{-1}$ (C-N stretching vibration), $1112.0 \mathrm{~cm}^{-1}\left(-\mathrm{NH}_{2}\right.$ characteristic absorption peak), $1038.3 \mathrm{~cm}^{-1}$ (- $\mathrm{SO}_{3}^{-}$stretching vibration), and $954.2 \mathrm{~cm}^{-1}$ (quaternary ammonium salt characteristic absorption peak) in the spectrum. As expected, the IR spectrum confirmed the presence of different monomers in ATGPA.

3.2. Elementary Analysis of ATGPA and AAGPA. The elementary analysis of ATGPA and AAGPA was carried out using a Vario EL-III elemental analyzer. The content of different element in these plugging agents can be obtained by detecting the gases, which are the decomposition products of the samples at high temperature. The test results of ATGPA and AAGPA are shown in Table 2.

3.3. Microscopic Structure. The microscopic structures of ATGPA and AAGPA were observed through SEM at room temperature. ATGPA and AAGPA solution samples $(0.6 \mathrm{wt} \%)$ were prepared with distilled water and cooled with liquid nitrogen, and then these samples were evacuated to keep original appearance as far as possible. As shown in Figure 3, the form of molecular coils was obviously changed when DMDAAC and AMPS were introduced into the AM/AA copolymer. Compared with the images of AAGPA, the network structure of molecular coils of ATGPA was closer than that of AAGPA, and the molecular coils of ATGPA possessed uneven surfaces due to the introduction of DMDAAC and AMPS.

3.4. Temperature Resistance. ATGPA and AAGPA solutions were prepared with distilled water. These plugging agents were placed at different temperatures for $72 \mathrm{~h}$. The apparent viscosity of these plugging agents was tested using Brookfield DV-III viscometer at different temperatures. The apparent viscosity versus temperature curves of ATGPA and AAGPA solutions are shown in Figure 4. Comparing with AAGPA, we could easily find that ATGPA owned better temperature resistance. The data indicated that ATGPA could withstand higher temperature and exhibited higher apparent viscosity at the same temperature. This phenomenon might be explained by the five-membered ring structure of ATGPA polymeric chains which could enhance the temperature resistance of this plugging agent. In addition, it might be attributed to 
TABLE 3: The parameter of core and the results of core plugging experiments.

\begin{tabular}{lccccccc}
\hline Plugging agent & Cores & Length $(\mathrm{cm})$ & Diameter $(\mathrm{cm})$ & Porosity $(\%)$ & $K_{\mathrm{wb}}(\mathrm{mD})$ & $K_{\mathrm{wa}}(\mathrm{mD})$ & $P_{R}(\%)$ \\
\hline ATGPA & $1 \#$ & 6.56 & 2.51 & 24.18 & 822.6 & 22.7 & 97.2 \\
AAGPA & $2 \#$ & 6.15 & 2.52 & 23.31 & 802.4 & 32.4 & 95.7 \\
\hline
\end{tabular}
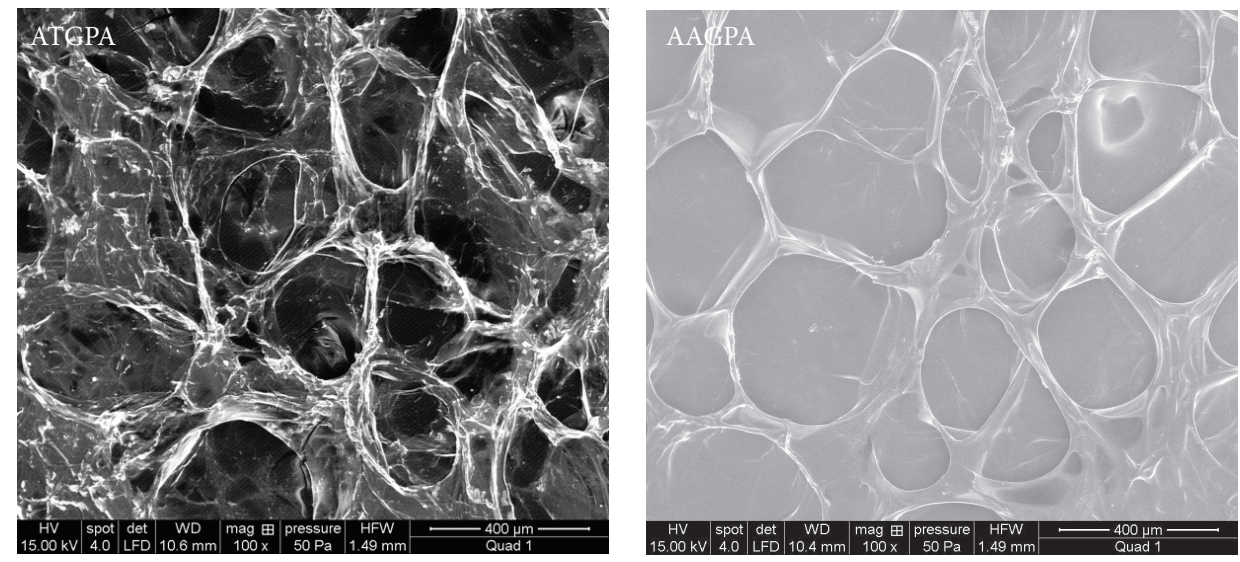

Figure 3: SEM images of ATGPA and AAGPA.

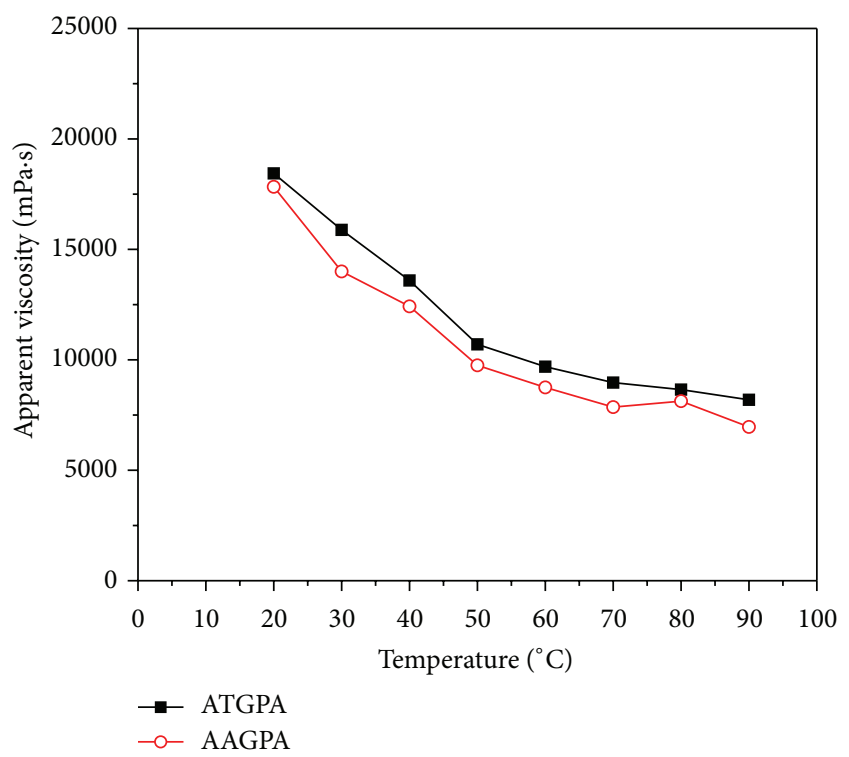

FIGURE 4: Apparent viscosity versus temperature for ATGPA and AAGPA. The apparent viscosity of these plugging agents $(0.6 \mathrm{wt} \%)$ was measured by Brookfield DV-3 viscometer at $7.34 \mathrm{~s}^{-1}$.

the $-\mathrm{SO}_{3}{ }^{-}$groups, which usually could improve the temperature resistance.

3.5. Salt Tolerance. The ability against $\mathrm{Na}^{+}$of ATGPA was shown in Figure 5(a). The salt tolerance of ATGPA was much more excellent than AAGPA. The tests about $\mathrm{Ca}^{2+}(0.6 \mathrm{wt} \%$, $65^{\circ} \mathrm{C}$ ) gave similar results (Figure $5(\mathrm{~b})$ ). These phenomena revealed that ATGPA could withstand higher salinity. And this may be related to the $-\mathrm{CONHC}\left(\mathrm{CH}_{3}\right)_{2} \mathrm{CH}_{2} \mathrm{SO}_{3}{ }^{-}$units on the chain of ATGPA. Comparing with $-\mathrm{CONH}_{2}{ }^{-}$groups the hydration layer formed by $-\mathrm{CONHC}\left(\mathrm{CH}_{3}\right)_{2} \mathrm{CH}_{2} \mathrm{SO}_{3}{ }^{-}$groups was more difficult to damage when neutralized with counter ions. Therefore, the salt resistance of ATGPA was better than AAGPA.

3.6. Viscoelasticity Measurements. ATGPA and AAGPA solutions $(0.6 \mathrm{wt} \%)$ were prepared with distilled water. These plugging agents were placed at $65^{\circ} \mathrm{C}$, and the time required for the formation of the gel was $72 \mathrm{~h}$. The viscoelasticity curves of ATGPA and AAGPA were shown in Figure 6. In the linear viscoelastic region, the elastic modulus $\left(G^{\prime}\right)$ of ATGPA and AAGPA was higher than the viscous modulus $\left(G^{\prime \prime}\right)$. This meant that the ATGPA and AAGPA are mainly based on elasticity. Compared with AAGPA, ATGPA exhibited higher $G^{\prime}$ and $G^{\prime \prime}$ under the same scanning frequency. This phenomenon might support that the adsorption type functional monomer could enhance the acting force between ATGPA molecular coils.

3.7. Plugging Ability. As shown in Table 3, the plugging rate of ATGPA $(0.6 \mathrm{wt} \%)$ was $97.2 \%$ at $65^{\circ} \mathrm{C}$. However, the plugging rate of AAGPA (0.6 wt $\%$ ) was $95.7 \%$ under the same conditions. The core plugging experiments results showed that ATGPA revealed more superior ability of core plugging. As shown in Figure 7, compared with AAGPA, ATGPA exhibited stronger antiscouring ability. In the subsequent water flooding process, the fluctuation of the injection pressure of ATGPA was relatively large, but there was no trend of decline. This phenomenon might support that the antiscouring ability was obviously improved in porous media due to the introduction of DMDAAC. 


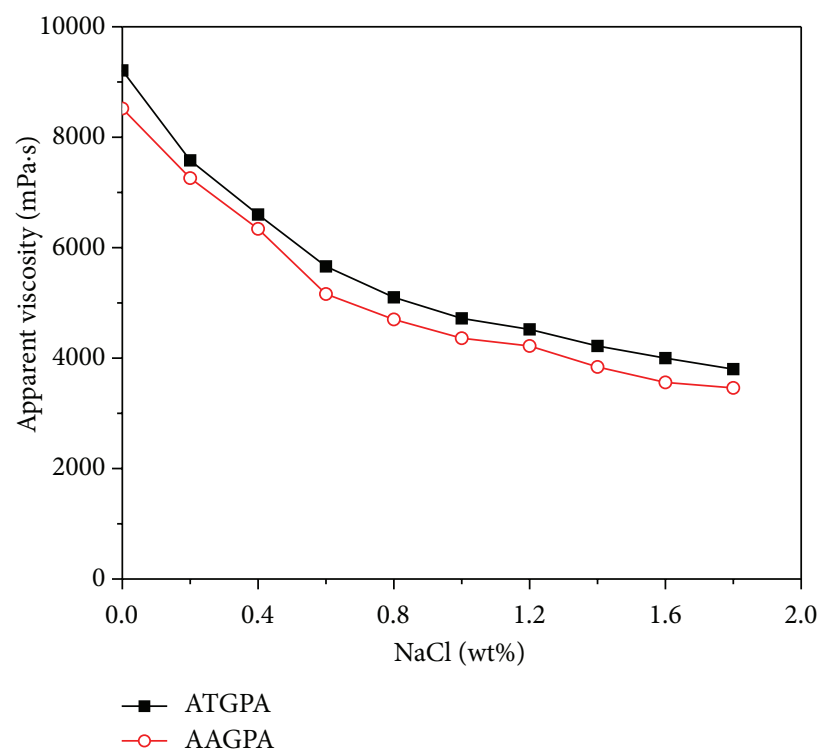

(a)

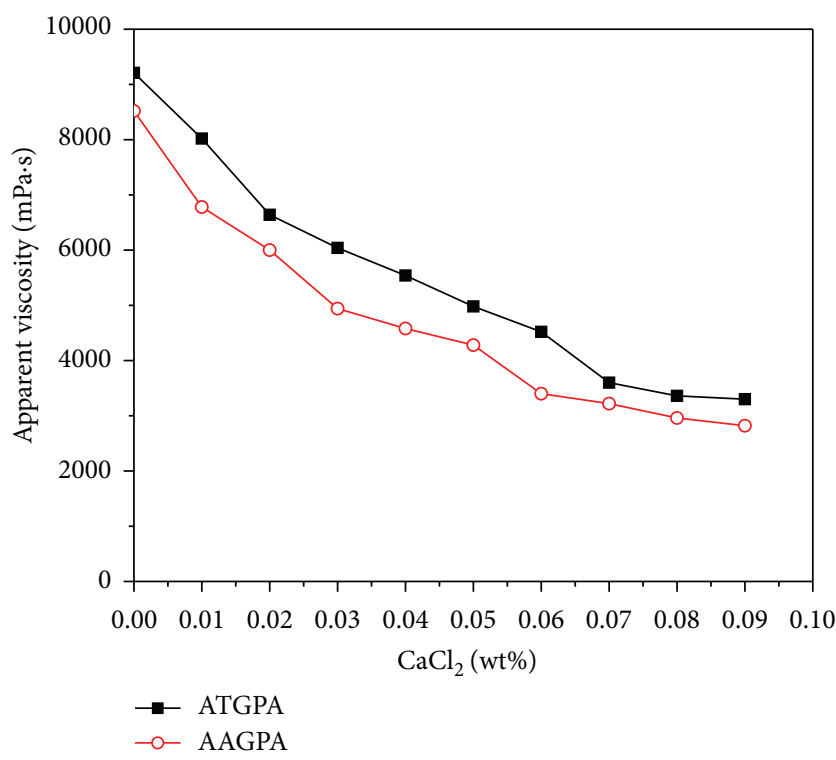

(b)

FIGURE 5: Salt tolerance ((a) $\mathrm{NaCl}$ and (b) $\mathrm{CaCl}_{2}$ ) of ATGPA and AAGPA (0.6 wt $\%$ ) at $65^{\circ} \mathrm{C}$. The apparent viscosity of these plugging agents was measured by Brookfield DV-3 viscometer at $7.34 \mathrm{~s}^{-1}$.

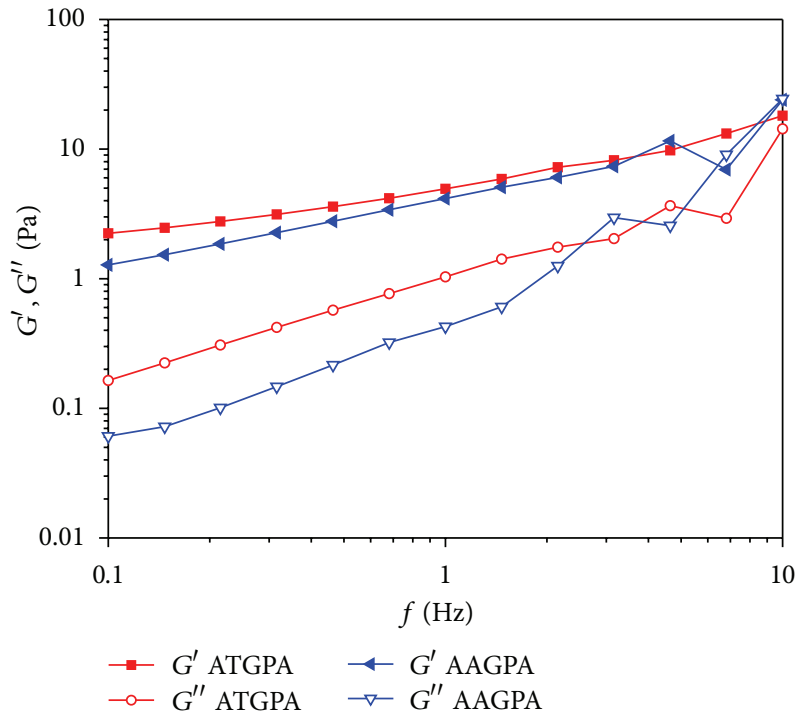

Figure 6: Viscoelasticity of ATGPA and AAGPA at $65^{\circ} \mathrm{C}$. These plugging agents $(0.6 \mathrm{wt} \%)$ were prepared with distilled water.

\section{Conclusions}

ATGPA was prepared using AM, AA, DMDAAC, AMPS, $\mathrm{HCHO}, \mathrm{C}_{6} \mathrm{H}_{6} \mathrm{O}_{2}$, and $\mathrm{CH}_{4} \mathrm{~N}_{2} \mathrm{~S}$ as raw materials. ATGPA was characterized by IR spectrum, elemental analysis, and scanning electron microscope. The solution properties, such as viscoelasticity, temperature resistance, salt tolerance, and plugging ability of ATGPA, were investigated under different conditions. The results indicated that ATGPA possessed moderate or good viscoelasticity, temperature resistance, salt tolerance, plugging ability, and antiscouring ability as EOR chemical.

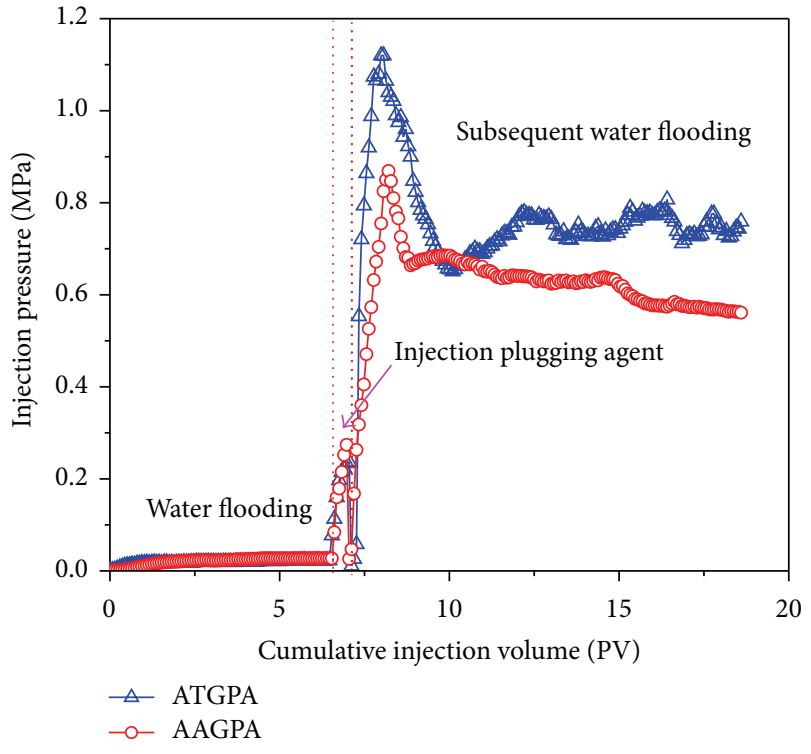

FIGURE 7: Core plugging experiments results of ATGPA and AAGPA $(0.6 \mathrm{wt} \%)$ at $65^{\circ} \mathrm{C}$.

\section{Conflict of Interests}

The authors declare no possible conflict of interests.

\section{Acknowledgments}

This work was supported by the Major Project of Jidong Oilfield (2013A06-08) and the Science and Technology Project of the exploration and production company (2014B-1113). 


\section{References}

[1] M. Lin, G. Zhang, Z. Hua, Q. Zhao, and F. Sun, "Conformation and plugging properties of crosslinked polymer microspheres for profile control," Colloids and Surfaces A: Physicochemical and Engineering Aspects, vol. 477, pp. 49-54, 2015.

[2] L. W. Niu, X. G. Lu, C. M. Xiong et al., "Experimental study on gelling property and plugging effect of inorganic gel system (OMGL)," Petroleum Exploration and Development, vol. 40, no. 6, pp. 780-784, 2013.

[3] Z. B. Ye, G. J. Gou, S. H. Gou, W. C. Jiang, and T. Y. Liu, "Synthesis and characterization of a water-soluble sulfonates copolymer of acrylamide and $N$-allylbenzamide as enhanced oil recovery chemical," Journal of Applied Polymer Science, vol. 128, no. 3, pp. 2003-2011, 2013.

[4] D. A. Z. Wever, F. Picchioni, and A. A. Broekhuis, "Polymers for enhanced oil recovery: a paradigm for structure-property relationship in aqueous solution," Progress in Polymer Science, vol. 36, no. 11, pp. 1558-1628, 2011.

[5] Z. Hua, M. Lin, J. Guo, F. Xu, Z. Li, and M. Li, "Study on plugging performance of cross-linked polymer microspheres with reservoir pores," Journal of Petroleum Science and Engineering, vol. 105, pp. 70-75, 2013.

[6] X. Yu, W. Pu, D. Chen et al., "Degradable cross-linked polymeric microsphere for enhanced oil recovery applications," $R S C$ Advances, vol. 5, no. 77, pp. 62752-62762, 2015.

[7] A. Mehrdad and R. Akbarzadeh, "Effect of temperature and solvent composition on the intrinsic viscosity of poly(vinyl pyrrolidone) in water-ethanol solutions," Journal of Chemical and Engineering Data, vol. 55, no. 9, pp. 3720-3724, 2010.

[8] C. R. Zhong, R. H. Huang, X. Zhang, and H. Dai, "Synthesis, characterization, and solution properties of an acrylamidebased terpolymer with butyl styrene," Journal of Applied Polymer Science, vol. 103, no. 6, pp. 4027-4038, 2007.

[9] C. J. Yao, G. L. Lei, L. Li, and X. M. Gao, "Preparation and characterization of polyacrylamide nanomicrospheres and its profile control and flooding performance," Journal of Applied Polymer Science, vol. 127, no. 5, pp. 3910-3915, 2013.

[10] A. Sabhapondit, A. Borthakur, and I. Haque, "Adsorption behavior of poly $(N, N$-dimethylacrylamide-co-Na 2-acrylamido-2-methylpropanesulfonate) on sand surface," Journal of Applied Polymer Science, vol. 91, no. 4, pp. 2482-2490, 2004.

[11] X. Zhao, L. X. Li, B. C. Li, J. P. Zhang, and A. Q. Wang, "Durable superhydrophobic/superoleophilic PDMS sponges and their applications in selective oil absorption and in plugging oil leakages," Journal of Materials Chemistry A, vol. 2, no. 43, pp. 18281-18287, 2014.

[12] Y. Zheng and A. Wang, "Nitrate adsorption using poly(dimethyl diallyl ammonium chloride)/polyacrylamide hydrogel," Journal of Chemical \& Engineering Data, vol. 55, no. 9, pp. 3494-3500, 2010.

[13] E. Guzmán, H. Ritacco, F. Ortega, T. Svitova, C. J. Radke, and R. G. Rubio, "Adsorption kinetics and mechanical properties of ultrathin polyelectrolyte multilayers: liquid-supported versus solid-supported films," Journal of Physical Chemistry B, vol. 113, no. 20, pp. $7128-7137,2009$

[14] J. O. Carnali and P. Shah, "Correlation of surfactant/polymer phase behavior with adsorption on target surfaces," Journal of Physical Chemistry B, vol. 112, no. 24, pp. 7171-7182, 2008.

[15] X.-J. Liu, W.-C. Jiang, S.-H. Gou, Z.-B. Ye, and X.-D. Xie, "Synthesis and evaluation of a water-soluble acrylamide binary sulfonates copolymer on MMT crystalline interspace and EOR,"
Journal of Applied Polymer Science, vol. 125, no. 2, pp. 1252-1260, 2012.

[16] X. Liu, W. C. Jiang, S. H. Gou, Z. B. Ye, and C. Luo, "Synthesis and clay stabilization of a water-soluble copolymer based on acrylamide, modular $\beta$-cyclodextrin, and AMPS," Journal of Applied Polymer Science, vol. 128, no. 5, pp. 3398-3404, 2013.

[17] X. Liu, W. Jiang, S. Gou et al., "Synthesis and evaluation of novel water-soluble copolymers based on acrylamide and modular $\beta$ cyclodextrin," Carbohydrate Polymers, vol. 96, no. 1, pp. 47-56, 2013.

[18] L. T. Shi, Z. B. Ye, Z. Zhang, C. J. Zhou, S. S. Zhu, and Z. D. Guo, "Necessity and feasibility of improving the residual resistance factor of polymer flooding in heavy oil reservoirs," Petroleum Science, vol. 7, no. 2, pp. 251-256, 2010. 

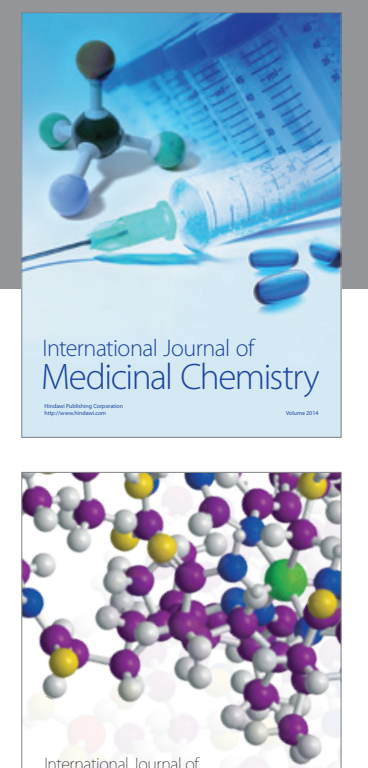

\section{Carbohydrate} Chemistry

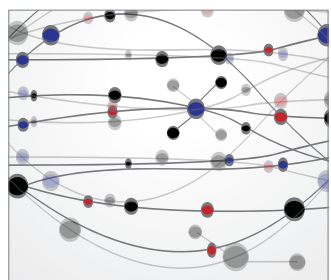

The Scientific World Journal
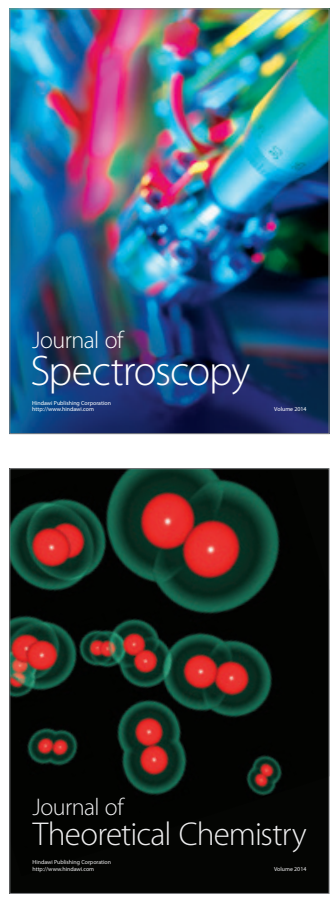
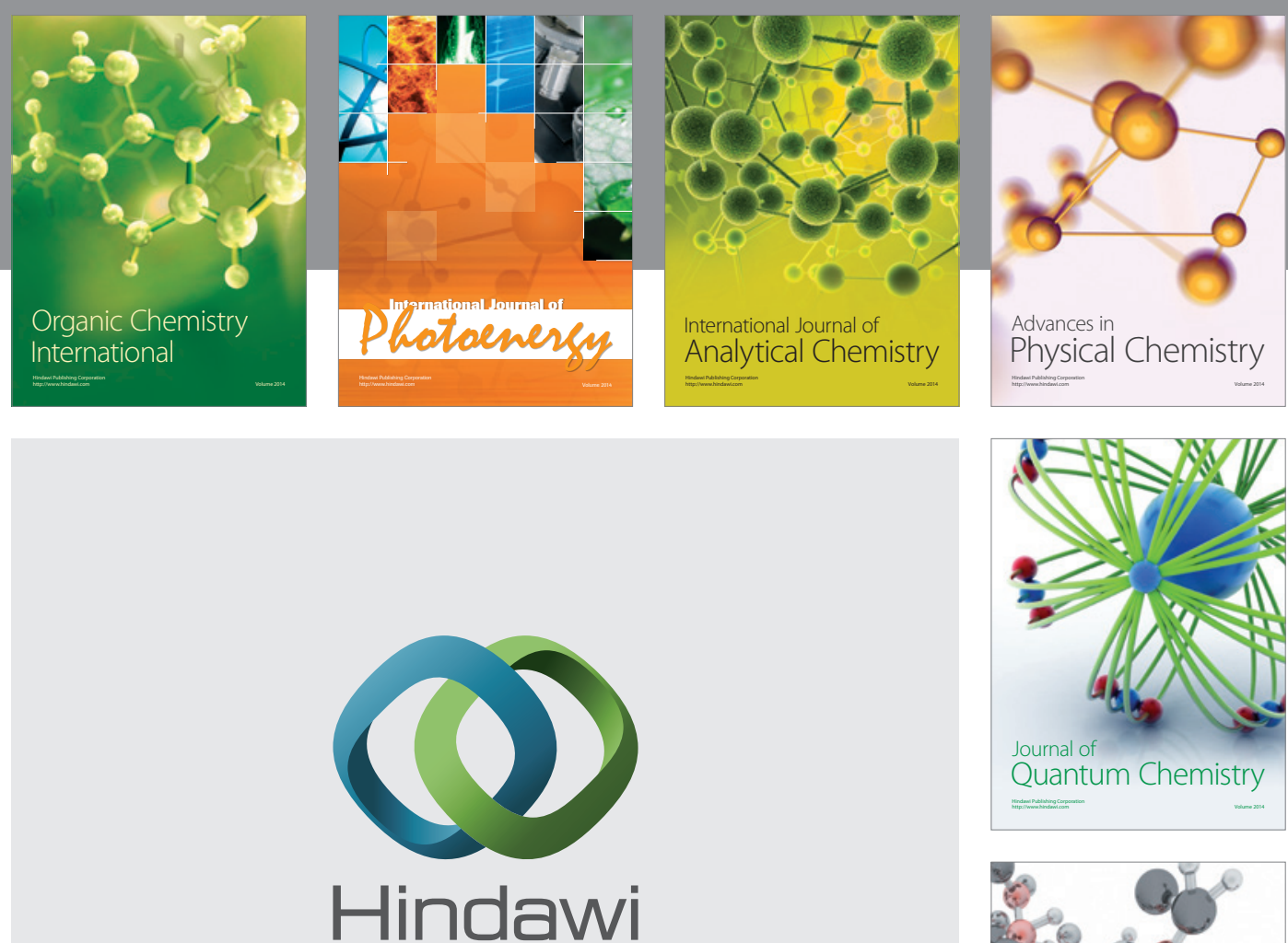

Submit your manuscripts at

http://www.hindawi.com

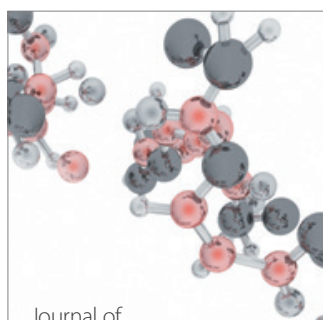

Analytical Methods

in Chemistry

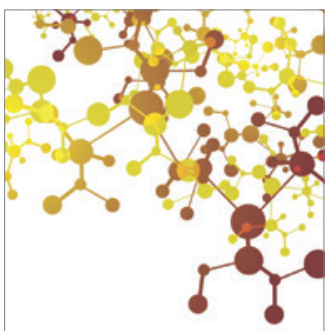

Journal of

Applied Chemistry

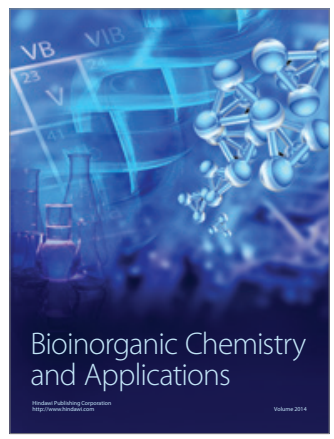

Inorganic Chemistry
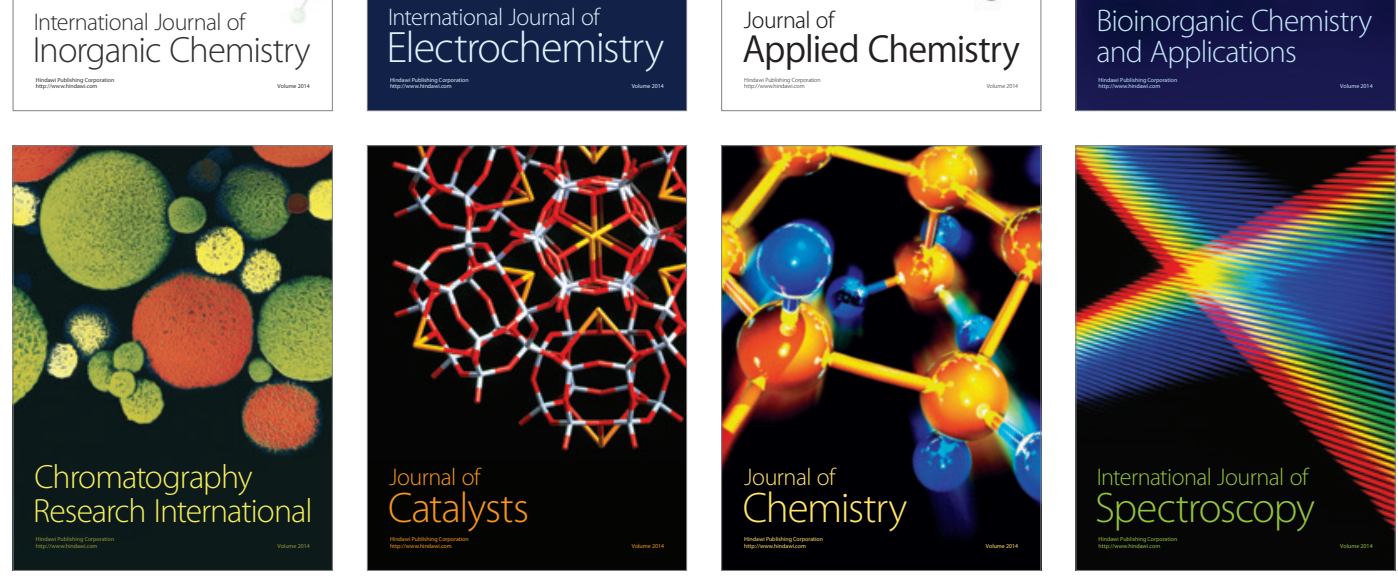